\title{
Knowledge sharing among workers: a study on their contribution through informal communication in Cyberjaya, Malaysia
}

Norizzati Azudin*

Faculty of Management, Multimedia University,

63100 Cyberjaya, Selangor, Malaysia.

E-mail: norizzati.azudin@mmu.edu.my

*Corresponding author

\section{Mohd Nor Ismail}

Faculty of Management, Multimedia University,

63100 Cyberjaya, Selangor, Malaysia.

E-mail: mohdnor.ismail@mmu.edu.my

\section{Zainab Taherali}

PO Box 4302, Baniyas Square,

Al Badoor Building, Deira, Dubai, UAE.

E-mail: zainab522004@yahoo.co.uk

\begin{abstract}
Malaysia, being a multi-racial society, faces the challenges of creating knowledge sharing capability in organisations, as cultural values are often reflected in the workplace by individual employees. For organisations, it is not clear whether this diversity has resulted in any form of competitive advantage. Studies have shown that various communities in Malaysia do not bring their respective cultures to work, and as such the company values prevail. This research is based on the demographic study of Informal Knowledge Sharing in Cyberjaya, Selangor, Malaysia. After twelve years, Cyberjaya is approximately $25 \%$ developed, gradually expanding with the establishment of multinational and international organizations. Several flagship applications have been developed in MSC Malaysia to accelerate its growth. However, the expertise and knowledge shared among the workers are doubtful, especially at its initial growth stage. As Knowledge Management (KM) developed, Communities of Practice (Wenger, 1998) became popular, even dominant 'KM' intervention. Soon it was supplemented with story-telling interventions encouraging knowledge workers to use stories to 'sell' KM internally, share knowledge and facilitate collaboration. This study will focus on knowledge sharing among workers, particularly the approach used to share knowledge through informal communication outside their organizations.
\end{abstract}

Keywords: Knowledge Sharing, Communication, MSC.

Biographical notes: Norizzati Azudin has a Bachelor of Arts (Hons) with Major in Media Studies and Minor in South East Asian Studies from Universiti Malaya (UM). She served Multimedia University (MMU) as Assistant Manager 
for four years while pursuing her Masters in Science (Corporate Communication) from Universiti Putra Malaysia (UPM). She has several years of experience working as Part Timer for TV3 and Radio DJ of RTM. She was also a Part Time teacher and trainers. She has been a lecturer in MMU for more than three years. She is the Assistant Head of Management Department under the Faculty of Management, Assistant Coordinator of BBA programme, University Student Affairs Committee Member, Self Appraisal Committee Member, a researcher, and, an active MMU's trainer. She is currently pursuing her $\mathrm{PhD}$ in International Trade.

Mohd Nor Ismail has a B Sc in Electrical Electronics Engineering and MBA from University of Southern California and Northrop University in Los Angeles, California, USA respectively. He served the Sapura Group of Companies - a local multi-national conglomerate for a period of 20 years, the last position being the Senior Vice President of Telecom Business Unit 3. He held various operational and corporate management responsibilities particularly in Quality Management, Manufacturing, Contract Management, Vendor Development, Business Development, International Marketing and Sales and Distributions. He also served at Puncak Niaga Sdn Bhd as Special Assistant to the Executive Chairman in-charged of Business Development. He is currently employed as Specialist in Management with the MMU Faculty of Management.

Zainab Taherali has obtained her undergraduate in International Business at National American University (USA). She persued her Master's Degree in Knowledge Management with Multimedia at Multimedia University (MMU, MALAYSIA). Currently she is working at the Australia Council for Educational Research(ACER) ACER is the world leading educational research centres, committed to creating and distributing research-based knowledge, products and services to improve learning across the lifespan in both formal and informal settings. She works with the main author for her Masters Degree and several publication, including this paper.

\section{Introduction}

Malaysia population is approximately 25 million people. The mix is comprised of diverse main races of Malay, Chinese, and, Indian. The majority Malay, sizeable Chinese, and, relatively smaller Indian community has its own identity, beliefs, and, traditions. In organizations, this diversity creates obstacles to creating knowledge sharing capability as cultural values are reflected in the workplace by individual employees (Woods, 2008). It is not easy to see how this diversity has been created, and whether it leads to any competitive advantage. However studies previously done (Fontaine, 2006), and proved that various communities in Malaysia do not bring their respective cultures to work, thus, making the company values prevailing (Woods, 2008).

In the heart of MSC Malaysia (2008) lies the first truly intelligent city, Cyberjaya (Neocyber, 2009). It was officially launched by the Malaysia's former Prime Minister, Tun Dr Mahathir Mohammad on 8th July 1999. The landmark event was witnessed by 25 of the world's top ICT personalities. Promising to be the city of the future, Cyberjaya continues to attract leading ICT companies of the world to locate their industries in the MSC Malaysia and undertake research, develop new products and technologies and export from this base. The MSC Malaysia is also an ideal growth environment for Malaysian ICT SMEs to transform themselves into world-class companies. Furthermore, 
the MSC Malaysia welcomes countries to use its highly advanced infrastructural facilities as a global test bed for ICT applications and a hub for their regional operations in Asia.

This research is based on the demographic study of knowledge sharing through informal communication in Cyberjaya, Selangor, Malaysia. The study would first start up by reviewing the history of Cyberjaya. Though conceived in 1996, the Asian Currency Crisis of the following year inhibit development, which was limited in the early years, and now after twelve years Cyberjaya is approximately one quarter developed, as essential development along with its primary roads, of which the 900 MSC status companies around 400 are in Cyberjaya (Woods 2008). Out of these, more than ten are multinationals with a substantial staff presence (more than 400 staff on average), an equal number of major Malaysian companies and a wide range of small medium enterprises including Joint-Ventures and Sponsored start up companies from Multimedia University (Woods, 2008) and other private individual initiatives. It is estimated that the daytime population is around 15,000 workers, of which a large number comprising of university students. The night time population is mostly university students (Woods, 2008).

\subsection{Knowledge Transfer Opportunities - Formal Structure - Flagship activities}

Several flagship applications have been developed in MSC Malaysia to accelerate its growth. They are focused on the development of Smart Schools, Telehealth, e-Business, smart card technology, electronic government, technopreneurship. Covering an area of 511.6 hectares or $18 \%$ of the Flagship Zone, it comprises of four enterprise sectors, an enterprise centre, and enterprise housing areas. Some 500 innovative IT companies are operating within this precinct, supporting a working population of 10,000 knowledge workers (Zainuddin, 1997). A new initiative of MSC Malaysia is the Creative Multimedia cluster, which aims to catalyze the development of the Malaysian creative content industry. While the flagship enterprises are predominately carried out by MDec itself there is some knowledge sharing particularly with university groups and some SMEs (Woods, 2008). Start-up activities are supported by both MDec and the Multimedia University, and incubator facilities are available. Though the primary support is financial and facilities, some technology transfer and expertise are also offered (Woods, 2008).

\subsection{Knowledge Spaces}

Denning (2000) in some practical advice on holding knowledge fairs recommends using circulation spaces as they ensure an audience, even if just passing. Architectural design has long acknowledged the possibilities for conversation and casual gathering on staircase landings, extended corridors and urban designers talk of 'urban rooms' where gathering naturally occurs. There appear to be critical proportions to such spaces as identified in research (Woods, 2002).

Woods (2008) stated that in Cyberjaya the average building footprint is about $40 \mathrm{x}$ 40 meters square and given the low plot ratio, adjacent building can be up to 100 meters apart. This is where development is continuous. Other buildings sit in isolation given the year round heat humidity and heavy rain; there is little willing pedestrian movement. The only time that people meet outside the office is at lunchtime and that generally involves using the car. Most staff in Malaysia eats outside the office. If any informal knowledge sharing takes place between workers from different firms it can only be at these times, as very few staff live in Cyberjaya. 


\subsection{Knowledge Sharing Culture in Malaysia}

As Knowledge Management (KM) developed, Communities of Practice (Wenger, 1998) became popular, even dominant, 'KM' intervention. Soon it was supplemented with storytelling (Denning, 2001) interventions encouraging knowledge workers to use stories to both 'sell' KM internally, share knowledge ad facilitate collaboration. More recently, Social Network Analysis (Cross \& Parker, 2004) is being used to discover the structure of relationship in existing communities (Firestone and McElroy, 2004). Knowing the importance of Knowledge Sharing as a part of Critical Success Factor in the implementation of Knowledge Management in an organization, the study touched the existence of Knowledge Sharing Culture in Malaysia Organization.

Chowdhury (2006) reported that one of the most challenging barriers hindering its wider adoption is people need to trust each other for knowledge sharing to happen spontaneously and efficiently, but in Asia, people basically do not trust each other, and, the knowledge that they each possess. People are also lack of confidence to share and exchange expertise. Another factor is the fear of being penalised. This, perhaps, should be considered the most challenging barrier to wider implementation of KM in Asia. Many people think that if they share knowledge and make their opinions openly available to others, they will lose out in someway.

Typically, that will either be in terms of losing their personal competitiveness the argument in favour of keeping what you know to yourself to enhance your own value ('knowledge hoarding') or the risk of incurring criticism from management for speaking out. It is much better, on balance, to stay silent. Perhaps that is why people are so reluctant to contribute to new ideas or to criticise openly (Chowdhury, 2006). However Chowdhury (2006) states that most KM models are formed in the context of a Western framework in which freedom of expression and individualism are both accepted social norms. This is though not necessarily the case in many organisations in Malaysia. Psychologists accept that Asians are generally less vocal and critical in the workplace compared to Westerners.

\section{Literature Review}

The literature review examines recent research studies. This acts as a basic proposed study. It also explains the need for the proposed work to appraise the shortcomings and/or informational gaps in secondary data sources. This analysis may go beyond scrutinizing the availability or conclusion of past studies and their data, to examining the accuracy of secondary sources, the credibility of these sources and the appropriateness of earlier studies (Cooper et al., 2003).

\subsection{Knowledge Sharing}

Sharratt and Usoro (2003) stated that "sharing is a process whereby a resource is given by one party and received by another", in addition to knowledge sharing: "It is the process by which individuals collectively and iteratively refine a thought, an idea or a suggestion in the light of experience" (Chua, 2003).

Knowledge sharing can be created in many forms such as: “...a story describing a similar experience whereby a method or technique was developed or used to solve a problem. If unable to provide a solution directly, knowledge may be shared in relation to contacting someone who might know and be willing and able to help" (Sharratt \& Usoro, 2003) 
It also must be supported by several social factors: "trust" (Schrader, 1990; McDermott and O' Dell, 2001 in Chua, 2003; Yang, 2004), "care" (von Krogh, 1998 in Chua, 2003), "emotional commitment and the quality of the relationship" (Weiss, 1999 cited in Chua, 2003). Trust is the most important factor in knowledge sharing (Tynan, 199 in Yang, 2004). If there is no trust, it is impossible for staffs to share, collaborate and communicate (Yang, 2004). ".....the greater the level of trust amongst people, the more the openness and effectiveness of the communication channel..." (Yang, 2004)

Furthermore, O' Dell and Grayson (1998) and VonKrogh (1998) in Chua (2003) emphasized the important of caring as one of the social factors that influence knowledge sharing. "When there is an absence of a strong personal tie that warrants listening to or helping each other, knowledge sharing is hampered" (O'Dell and Grayson,1998; vonKrogh,1998 in Chua, 2003)

Individual also must have emotional commitment in order to volunteer him/.her for sharing the knowledge (Weiss, 1999 cited in Chua, 2003).Without emotional commitment; they may not want to share their knowledge in order to keep improving their power (French and Raven, 1959 in Yun and Allyn, Jan 2005).

The last social factor is the quality of the relationship. In the large organization, members may not be aware of someone who would be interested in the knowledge they have or has the knowledge they require (Chua, 2003). This situation happens, because of the lack of relationship between members of the organization (Chua, 2003).

\subsection{The importance of Knowledge Sharing}

Gurteen (1999) found four importance values of knowledge sharing:

1. Knowledge is an intangible product which includes ideas; processes and information. These intangible products are taking a growing share of global trade from the traditional, tangible goods of manufacturing economy.

2. Knowledge sharing is important for creating a new knowledge in order to achieve competitive advantage.

3. Knowledge sharing is important because of the increasing turn over of staff. People do not keep the same job for life any more. When someone leaves an organization their knowledge walks out of the door with them. Therefore, sharing has the power to carry on the knowledge.

4. Many organizations have problem of "we don't know what we know". Expertise learnt and applied in one part of the organization is not leveraged in another.

5. Accelerating change in technology, business and social " 50 percent of what we knew 5 years ago in probably obsolete today".

Sharing knowledge allows both parties not only to retain information but also to amplify and expands it through the exchange process. However sharing of knowledge within organisations provides the opportunity to discuss know-what and know-how practices, to direct the organisation towards future development and growth. The act of it transfers knowledge from one person to another or among many people adding value to organizational activities (Mitchell, 2008).

\subsection{The Importance of Knowledge Sharing Culture in Organization}

Many organizations have intranets to enable employees to share, exchange, and access knowledge but if non-sharing culture exist there will be little benefit for the organization or its employees. It is possible that employees may not find the intranets user friendly, therefore there is likely to be resistance to sharing knowledge through that system, or for some it may simply be too much of a hassle to try find what is being sought. Where resistance to sharing knowledge attitudes exist, organizations need to consider 
undertaking an approach to implementing behavioural patterns amongst staff that are helpful to knowledge sharing. "Resistance in lack of sharing knowledge deprives others of opportunity to gain knowledge and can in fact bounce back on those who are not willing to share" (Mitchell, 2008).

Organizational culture has connection with knowledge sharing and knowledge transfer. Knowledge Transfer and Knowledge sharing is a concept and can be formal and informal. Formal Knowledge sharing however is more common among staff's in organization (Naaranoja \& Sandhu, 2007).

Studies show that culture can make or crack hard work to manage knowledge effectively within an organization (Choo \& Bontis, 2002). Lawson's research study included the test of studies to understand what cultural types or cultural values were found to be most important to the implementation of effective Knowledge Management practices. One study Lawson,(2004) described was by Lesser and Storck (2001) study concluded that communities of practices provided value to an organization and can be used as a means to enhance performance and improve quality within any organization or company.

According to Nonaka and Takeuchi (1995), Knowledge sharing culture consists of collection and combination of ordinary expectation, share experience, tacit roles and social standard and norms that create our attitude and behaviours. Gold et al. (2001) pointed out that Knowledge sharing culture in organization should support and motivate their employee in any knowledge sharing activities during interaction and relations building to overcome the barriers for implementing the KM. According to O'Dell and Grayson (1998), people like to share partly because they wanted to let other people know of what knowledge they hold. The people like a kind of respect they earned from others. If for any specific reason they cover up knowledge, it was organizational environment, political setting or reward system that caused them to prevent from sharing and collaboration (O’Dell and Grayson, 1998).

Culture, according to Vijay Sathe is "the set of important understandings (often unstated) that members of a community share in common." These shared understandings consist of our norms, values, attitudes, beliefs and 'paradigms'. Another definition given in Webster's New Collegiate Dictionary "culture is the integrated pattern of human behaviour that includes thought, speech, action, and artefacts and depends on man's capacity for learning and transmitting knowledge to succeeding generations". This second definition is an exciting one as increasing our capacity for learning and transmitting knowledge is one of the prime aims of Knowledge Management (Gurteen.com, 2009).

Gurteen ,(1999) states that; "I don't believe you can make people share by overtly rewarding them. We are not laboratory pigeons. Stimulus-response does not work in complex systems. Human beings are motivated by more than just money". Yes, ensure appropriate rewards are in place if you must but I feel its better to ensure that disincentives to sharing are removed.

\subsection{Overcoming the Objections to Knowledge Sharing}

Some people object to sharing as they feel that others will steal their ideas and reap the rewards rightly theirs. This is a fallacy. Knowledge sharing isn't about blindly sharing everything; giving away your ideas; being politically naïve; or being open about absolutely everything. You still need to exercise judgement. If you have a great idea don't share it with a competitor - external or internal but on the other hand don't try to develop it on your own and don't sit on it for fear of it being stolen from you. Figure out how you can bring it to fruition by collaborating with other people (Gurteen, 1999). 
Further more Gurteen ,(1999) indicated that there is also another fallacy embedded in this thinking knowledge sharing is not just about sharing great ideas it's about improving the way that things get done by sharing the little things. You have lots of knowledge of little use to you share it with others who can make use of it and in return they will share relevant knowledge with you.

\subsection{The Role of Story Telling and Water Cooler Talks}

Regular meetings for the purpose of discussing work-related experiences provide an avenue for sharing knowledge that generates a collaborative environment and one through which everyone benefits. A valuable avenue for knowledge sharing occurs during social interaction be it in the corridor, or at the water cooler, or a chat over lunch, and it is not uncommon in those discussions for story telling to be used to illustrate examples of points to be made (Mitchell, 2008).

However Mitchell (2008) states that good stories should be entertaining and also they should memorable and people centred. They also suggest that stories 'encourage creativity, help in handling emotion, help to make sense of puzzling situations, co-evolve with the organisation's culture.

The same story repeated often sends signals about the cultural life of an organisation. According to the author, stories and experience are linked, meaning stories transform into experience and experience turns into stories and says that storytelling goes on almost continually. It is evident from those views that stories carry a tremendous responsibility and not enough attention is being paid to their value.

People like to tell stories, and people enjoy listening to them even though there may be doubt surrounding the truth of what is being said. Socialising in a formal or informal way provides opportunities for stories to be told as people relate their experiences and it is through the medium of story telling that people are encouraged to share knowledge (Mitchell, 2008).

In a conference paper (No Doubt Research, 2001) presented in Auckland it states that the 'water cooler' is simply a metaphor for any number of different 'talk spaces' where staff can meet and talk informally. That some obvious ways that organisation can create such spaces are:

1. Dedicated Talk Spaces: These can be as simple as the areas around the water cooler or coffee pot, or as sophisticated as dedicated 'chill out' rooms. The point of creating such spaces is that it provides opportunities for staff to be able to talk with one another in an informal setting. Although much office 'gossip' is not about work, a great deal of staff talk about it. The conversations staff have with one another are 'the way knowledge workers discover what they know, share it with their colleagues, and in the process create new knowledge for the organization' (Davenport \& Prusak, 1998:90).

2. Smart Office Layout: In some organisations, the need for 'talk zones' is obviated by the layout of the office. One organisation we work with discovered they didn't need more water coolers or sofas because they were a small team in an open-plan office, with a culture that encouraged mingling.

3. Dedicated Knowledge Sharing Events: Think about organising a 'knowledge fair'or some kind of open forum where staff can share their knowledge. The term 'Knowledge fair' sounds extreme but really just means any opportunity for staff to meet and talk to other staff about their work.

4. Knowledge Leaders: No knowledge management initiative will work without someone senior in the organisation taking responsibility for it. This is the person 
who marshals the resources, champions the logic of knowledge sharing, enrols the participation of staff, and models knowledge sharing behaviours.

Organisations can exploit the existing informal peer-to-peer knowledge transfer mechanisms already existing in their workplaces. The two most important reasons why organisations should think about pursuing these informal mechanisms are because they are (i) remarkably effective up to $70 \%$ of workplace learning occurs in them, and, (ii) remarkably cost effective.

However Steinlin, (2005) in his research he says that one of the few ways to optimise workspace to help in knowledge sharing are:

1. Mix ' $n$ match: Put people from different sectors/divisions in rooms together so they know what the others are doing. More room for cross-fertilisation! Is there a specific person/section for coordination of knowledge sharing? Or other people critical for this function (knowledge brokers)? Put them at a 'busy intersection' of the building (e.g., near the entrance) where people pass by a lot, so everyone knows who they are and people will drop by a lot.

2. Share lunch: This is the ideal opportunity for knowledge sharing between colleagues who may not do so during regular business.

3. Along the same lines put a nice 'standing table' in an open hall-area, near the coffee machine. Spontaneous knowledge sharing is guaranteed to occur. Also, include a few comfortable corners/spots where people can have informal meetings, and notice boards or pin boards near each department for people to hang up their announcements or posters or etc.

As such, the 'water cooler' approach to knowledge management not only provides a soft entry option but also the natural starting point for the knowledge management Programme. This 'water cooler' approach will not deliver a mature Knowledge management culture on its own. Indeed, simply expanding the Informal mechanisms already in place may well necessitate a change in workplace culture. http://www.nodoubt.co.nz/pdfs/knowledge_management/watercooler_km.pdf

\subsection{Formal vs. Informal Knowledge Sharing Practices in Organization}

Informal knowledge sharing is the communication outside the formal organisational structure that fills the organisational gaps, maintains the linkages, and handles the onetime situations (Jewels, Underwood \& de Pablos, 2008).

Informal learning also takes place through daily social interactions such as participation in group activities, working alongside others, tackling challenging tasks, and working with clients; the success of these forms of informal learning is highly dependent upon the quality of human relationships in the workplace (Eraut, 2004).

Berg (2008) indicates Informal learning is often described by contrasting it with formal learning. Formal learning can be likened to riding a bus, as the route is preplanned and the same for everyone. Informal learning, then, is more like riding a bike in that the individual determines the route, pace, etc. (Cross, 2007). Informal learning is "predominately unstructured, experiential, and no institutional" (Marsick \&Volpe, 1999).

Informal learning can take a reactive form, where the learning was unplanned but still recognized by the learner retrospectively. Informal learning can be incidental and integrated into daily activity. It can also be intentional, and potentially somewhat structured (Simpson, 2006).

However, the research seems to show inconsistent results. For example, in Tikkanen's (2002) and Kremer's (2005) studies, less experienced, younger workers reported engaging in more informal learning, while more experienced, older workers 
were less likely to engage in informal learning activities and tended to view their informal learning as being less embedded in the work.

Furthermore it describes that there are basically two types of networks one is formal network which is known as prescribed networks those that are composed of a set of formally specified relationships between superiors and subordinates and among functionally differentiated groups that must interact to accomplish an organizationally defined task. On the other hand second one is informal networks which is known as emergent networks involve informal, discretionary patterns of interaction where the content of the relationship may be work related, social, or a combination of both.

Formal knowledge sharing initiatives could be considered as a top-down approach. Secondly it has however clearly evident that employee in an organization uses an alternative method of knowledge sharing to the one created by management. Individuals perform their own personal networks and develop their own 'communities of interest' in what could be considered as an informal bottom-up approach (Jewels, Underwood \& de Pablos, 2008).

It has examined that other then formal and informal knowledge sharing there are also other two types of sharing which is market knowledge; public and private knowledge. They defined public knowledge as the knowledge reported through standard instruments such as company reports, audited financial statements, price quotes etc. Second is private they defined private knowledge as knowledge that is not publicly available or guaranteed by third parties. For example sharing of comparative, objective, and unrestricted information (Laila, 2007).

Knowledge-sharing networks do not exist in some isolated bubble by themselves. Elements such as basic organizational structure and existing conditions of uncertainty play a crucial role in understanding knowledge sharing patterns between units (Laila, 2007).

Focusing on the formal hierarchical structure as a coordinating mechanism, while ignoring the informal lateral relations seems to inhibit the sharing of private non codified knowledge (Laila, 2007).

This is the type of knowledge that most researchers and practitioners believe is the most valuable knowledge in terms of its uniqueness and its importance for innovation in the emergent knowledge economy (Laila, 2007).

Dori, (2000) states that on a parallel track, however, there's a growing recognition that valuable learning often takes place through informal learning. Informal learning is based in conversations, social interactions, and team projects, in which learning is part of the interactions between people. It has been acknowledged as one of the key reasons for forming communities of practice, networks, and other forums that allow people to network and socialize. Informal learning isn't limited to a predefined body of knowledge, but rather emerges from the interaction of people. At the heart of it is the transfer of tacit knowledge-knowledge that's not articulated but is acquired by individuals through experience.

Peter Senge, (2000) of the Society of Organizational Learning states that all knowledge is generated in working teams. He sees working and learning as inseparable. Through forming relationships, knowledge is diffused. He alludes to the image of the village square, where people hang out in a social space. That social space is the setting in which social relations are reinforced, trust is developed, and informal learning takes place. In sum, informal learning is that which allows the tacit knowledge resident in a group to emerge and be exchanged, sometimes by serendipity, sometimes in the course of accomplishing a specific project, through the construction of spaces that support learning. 
Looking at the chart below, we can see four modes of learning and the methods associated with each pair: formal and informal, and, face-to-face and virtual.

\begin{tabular}{|c|c|c|}
\hline & FORMAL & INFORMAL \\
\hline FACE-TO-FACE & $\begin{array}{l}\text { COURSES } \\
\text { SEMINARS } \\
\text { WORKSHOP }\end{array}$ & $\begin{array}{lr}\text { NETWORKING } & \text { EVENTS } \\
\text { TEAM } & \text { PROJECTS } \\
\mathbf{3} & \end{array}$ \\
\hline VIRTUAL & $\begin{array}{l}\text { Tele/VIDEOCONFERENCES } \\
\text { E-MEETINGS } \\
\text { ONLINE COURSES }\end{array}$ & $\begin{array}{l}\text { Web - Based collaborative } \\
\text { spaces } \\
\mathbf{4}\end{array}$ \\
\hline
\end{tabular}

Source: Adapted from Dori Digenti (2000) Make space for informal learning. http://www.learningcircuits.org/2000/aug2000/digenti.html

As organizations rapidly move their training focus to virtual environments, a proliferation of methods to support formal learning has appeared: teleconferencing, videoconferencing, e-meetings, and online courses (quadrant 2 ). The move to virtual delivery often involves combining a body of knowledge with resource links, interactive segments, personalization features, and other bells and whistles. Yet, even in the innovative uses that make the learning experience more engaging and possibly more effective, the underpinnings are still those of formal learning.

Furthermore Dori, (2000) focusing on quadrant 3 above, we can see that in the brief history of informal, face-to-face learning, a number of structures have evolved to support learning. These include:

i. Temporary learning systems: groups of people brought together for a short period of time to learn about a specific topic

ii. Communities of practice: groups of people that share "ways of working" or professional or personal interests and who meet together to exchange knowledge and share resources

iii. Learning networks: cross-organizational groups focused on knowledge sharing within an industry or focused on a specific business issue.

The success of those forums for informal learning is the fact that members find themselves in a defined container or collaborative space for here-and-now learning. The new challenge for e-learning is to create these informal networks virtually and achieve the same benefits as face-to-face venues-that is, to create collaborative learning spaces in which informal learning can occur (quadrant 4).

\subsection{Perspective and Enabling Knowledge Sharing in Conversations}

Conceiving knowledge not as a static object or unit, but rather as a dynamic, context dependent process and action which raises the prerequisites for truly successful knowledge sharing. A dynamic view of knowledge emphasizes that knowledge is created, shared, integrated, or Applied in social interactions (Nonaka \& Takeuchi, 1995) and faceto-face conversations still represent the typical form of these interactions. If knowledge is viewed as an object (Alavi \&Leidner, 2001), knowledge can be embedded and stored in individual members, in roles and Organizational structures, in procedures and practices, in the organization's culture, and in the Physical structure of the workplace (Walsh \& Ungson, 1991). Accordingly, knowledge can be possessed (Cook \& Brown, 1999) and transferred to new potential owners by moving the 'knowledge reservoirs'.

If we conceive knowledge and knowledge sharing as dynamic processes of knowing, the central role of face-to-face conversations for knowledge sharing becomes evident 
(Alavi \& Leidner, 2001). Conversations are not "limited to a merely additive back and forth Exchange of information" or of knowledge. "It can also afford the generation of new Knowledge, since each remark can yield new meaning as it is resituated in the evolving Context of the conversation" (Cook \& Brown, 1999, p.393).

In conversations, it becomes apparent that the existing knowledge is not simply transferred, but is regenerated in a new context. Therefore, conversations represent a major means of how people interact and engage in knowing, sense making (Kurtz and Snowden, 2003) and knowledge sharing. According to Weick, it is through meetings, conversations, and other forms of communication that organizational members make sense of their daily actions (Weick, 1979, p.133-134). Conversations allow a coconstruction of meaning. They are interactive and iterative and let participants ask clarifying questions, deepen certain aspects, and ask for the larger context of a specific piece of information: all of which are activities that lead to the re-construction and regeneration of knowledge in a new context.

Conversations also create a shared experience (Dixon, 1997); they build trust and strengthen the relationships between the participants (Harkins, 1999) a prerequisite for effective Knowledge sharing (Szulanski, 1996). All of these factors are fundamental conditions for the Sharing of knowledge. Von Krogh, Ijicho, and Nonaka (2000) believe that "good conversations are the cradle of social knowledge in any organization, they allow the first and most essential step of knowledge creation: sharing tacit knowledge within a micro community" (von Krogh et al., 2000, p.125). One could argue that the strength of conversations consists in the fact that they are highly flexible and can be easily adapted to the situation, to the topic, and the people who participate in a discussion. While some conversations would suffer from too much structure or management (for example informal coffee-break chats or very emotional or intimate talks), many knowledge-intensive conversations can benefit from a clearer structure and more consistent management. Various authors point out rules and principles that regard the outer context of Conversation i.e. the situation in which the conversation takes place.

Mengis and J. Eppler (2005) states that concern the mix of conversation participants: all the participants together must bring the necessary knowledge into the conversation in order for it to achieve its goal. In addition, certain authors see a great advantage in including a facilitator who leads the conversation, but who, at the same time, always backs out of this leading position.

The physical space in which the conversation takes place influences the quality of conversations considerably. Suggestions include arranging participants in a circle or organizing the meeting in a location outside the organization's walls. Harkins suggests that in doing the latter, in closing the doors on the everyday context, the conversers will open up and have a more distant, external view of the issue (Harkins, 1999).

Another important set of rules regards the general conversational 25 etiquette and the conversational culture in which the conversation takes place. Von Krogh argues for the importance of explicitly communicating the conversational rules (von Krogh and Roos, 1995). Ross points out the importance of creating a safe haven and an open and trusting atmosphere (Beer \& Eisenstat, 2004; Ross, 1994). 


\begin{tabular}{|l|l|}
\hline $\begin{array}{l}\text { Assorted People \& Roles } \\
\text { - Ensure that relevant information and individuals are } \\
\text { present at the conversation, e.g. involve generalists. } \\
\text { - Assign a 'facilitator' who 'holds the context' of } \\
\text { dialogue }\end{array}$ & $\begin{array}{l}\text { (Gratton \& Ghoshal, 2002; } \\
\text { von Krogh \& Roos, 1995). }\end{array}$ \\
\hline $\begin{array}{l}\text { Allocated Time and Conversation Formats } \\
\text { - Create time and space for (emotive) conversations }\end{array}$ & (Gratton \& Ghoshal, 2002) \\
\hline $\begin{array}{l}\text { Supporting Space } \\
\text { - Choose and arrange the physical space of a } \\
\text { conversation so as to facilitate a certain type of } \\
\text { conversation (sitting in circles, blocking out } \\
\text { interruptions, holding meetings outside the walls of } \\
\text { the organization, etc.) }\end{array}$ & \\
\hline $\begin{array}{l}\text { Shared Conversational Culture } \\
\text { - Establish a conversational etiquette and } \\
\text { communicate it at the beginning of meeting. } \\
\text { - Make the type of conversation (e.g. strategic } \\
\text { conversations) explicit. }\end{array}$ & $\begin{array}{l}\text { (Beer \& Eisenstat, 2004; } \\
\text { - Create a safe haven for participants by making 1999) } \\
\text { openness and trust the rule rather than the exception } \\
\text { and by encouraging and rewarding the injection of } \\
\text { new perspectives. }\end{array}$ \\
(von Krogh \& Roos, 1995) \\
(Ross, 1994) \\
\hline
\end{tabular}

Source: Adapted from Jeanne Mengis andMartinJ. Eppler (2005). Understanding and

Enabling Knowledge Sharing in Conversation:

A literature Review and Management Framework.

\section{Research Methodology}

In this chapter, results were validated through primary data from the knowledge workers working in Cyberjaya with an exploratory study through questionnaires distribution. Due to the nature of time and resource constraints of this research, it is not feasible to conduct face-to-face meetings and interviews during lunch time since people have limited time breaks and have to return to their individual workplaces. As result, questionnaires were only distributed to 50 respondents who work in the heart of MSC area in Cyberjaya. 


\section{Data Analysis}

\subsection{Informal Knowledge Sharing Analysis}

This part contains the analysis of the questionnaire result focusing on the Knowledge Sharing environment during lunch time in Cyberjaya. There were eight questions which have been analyzed in this section. However, this section will be analyzed into two parts female and male, what males most share and what most females share during lunch. The data has been analyzed merely based on the total respondents and demographic factors.

\subsubsection{Estimation of Males with Whom They Have Lunch Most Frequently}

Table 4.1.1 Lunch accompanying persons for males

\begin{tabular}{|l|l|l|l|}
\hline Topic & Options & Frequency & Percentage \\
\hline \multirow{2}{*}{$\begin{array}{l}\text { Lunch } \\
\text { accompanying } \\
\text { persons for } \\
\text { males }\end{array}$} & Office Colleagues & 13 & $48 \%$ \\
\cline { 2 - 4 } & Friends & 11 & $41 \%$ \\
\cline { 2 - 4 } & Family & 2 & $7 \%$ \\
\cline { 2 - 4 } & Alone & 1 & $4 \%$ \\
\hline
\end{tabular}

From the table 4.1 .1 above shown, $48 \%$ of males prefer having lunch with office colleagues, while $41 \%$ with friends. However those who have lunch with their family are $7 \%$ and $4 \%$ of them have lunch alone. This shows that most of knowledge sharing is shared during lunch time with office colleagues and friends.

Table 4.1.2 lunch accompanying persons for females

\begin{tabular}{|l|l|l|l|}
\hline Topic & Options & Frequency & Percentage \\
\hline $\begin{array}{l}\text { Lunch } \\
\text { accompanying } \\
\text { persons for } \\
\text { females }\end{array}$ & Office Colleagues & 11 & $48 \%$ \\
\cline { 2 - 4 } & Friends & 11 & $48 \%$ \\
\cline { 2 - 4 } & Family & 1 & $4 \%$ \\
\cline { 2 - 4 } & Alone & 0 & $0 \%$ \\
\hline
\end{tabular}

\subsubsection{Estimation of Females with whom they have lunch most frequently}

From the table 4.1.2 shown above, females prefer having lunch with office colleagues, and friends are $41 \%$, while those who have lunch with their family are $4 \%$ and none of them have lunch alone. However compared to males, females also have most of knowledge sharing during lunch time with office colleagues and friends.

From the illustrations and the tables above, it can be concluded that the most significant result on both males and females were from office colleagues and friends where Knowledge worker mostly have their conversation are with friends and other employees. 
Based on gender overall result for both males and females participants have lunch with, $48 \%$ have with office colleagues, $44 \%$ have with friends and the smallest result comes from family and alone.

\subsubsection{How many people do you usually have lunch with?}

Table 4.1.3 No. of people having lunch with

\begin{tabular}{|c|c|c|c|}
\hline \multicolumn{4}{|c|}{ No. of people have lunch with } \\
\hline Topic & Options & Frequency & Percent \\
\hline \multirow{4}{*}{$\begin{array}{l}\text { No. of people } \\
\text { having lunch } \\
\text { with }\end{array}$} & one & 5 & $10 \%$ \\
\hline & two & 10 & $20 \%$ \\
\hline & three & 15 & $30 \%$ \\
\hline & more than three & 20 & $40 \%$ \\
\hline
\end{tabular}

The number of participants each participant has lunch with during information/knowledge sharing result is shown in Table 4.1.3 as above. The data shows that $40 \%$ of them have lunch with more then three people. However, the rest of the respondents' responses were within a group of three to two people. This shows that Knowledge workers prefer to come in a group of more than three people where more ideas can be shared with each other to learn new things and so on.

\subsubsection{Estimation of What Males mostly talk about at lunch?}

Table 4.1.4 Lunch Time Talks Males Estimation

\begin{tabular}{|l|l|l|l|}
\hline \multicolumn{4}{|l|}{ Lunch Time Talks Males Estimation } \\
\hline Topic & Options & Frequency & Percentage \\
\hline $\begin{array}{l}\text { At lunch } \\
\text { mostly talk } \\
\text { about? }\end{array}$ & Office Matters & 14 & $52 \%$ \\
\cline { 2 - 4 } & Hobbies/Entertainment & 6 & $22 \%$ \\
\cline { 2 - 4 } & Political/Current Affairs & 4 & $15 \%$ \\
\cline { 2 - 4 } & Gossips & 1 & $4 \%$ \\
\cline { 2 - 4 } & & 2 & $7 \%$ \\
\hline
\end{tabular}

It is shown in Table 4.1.4 that $52 \%$ of the males mostly talk about office matters related to their companies project, development of the organizations, meetings and so on. Meanwhile, $22 \%$ of them talk about hobbies/entertainment such as about movies, fashions lifestyles etc. Furthermore $15 \%$ of them discuss about political/current affairs 
politics which could be related to office politics or world politics. However it shows that $4 \%$ of males are involved in gossiping. $7 \%$ were found to be in the others category which the respondents mentioned they talk about food, work or just anything in general.

\subsubsection{Estimation of What Females mostly talk about at lunch?}

Table 4.1.5 Lunch Time Talks Females Estimation

\begin{tabular}{|l|l|l|l|}
\hline \multicolumn{3}{|l|}{ Lunch Time Talks Females Estimation } \\
\hline Topic & Options & Frequency & Percentage \\
\hline $\begin{array}{l}\text { At lunch } \\
\text { mostly talk } \\
\text { about? }\end{array}$ & Office Matters & 9 & $39 \%$ \\
\cline { 2 - 4 } & Hobbies/Entertainment & 4 & $17 \%$ \\
\cline { 2 - 4 } & Political/Current Affairs & 3 & $13 \%$ \\
\cline { 2 - 4 } & Gossips & 7 & $30 \%$ \\
\cline { 2 - 4 } & Others & 0 & $01 \%$ \\
\hline
\end{tabular}

Based on above Table 4.1.5, they show that $39 \%$ of the females talk about office matters as compared to male's analysis. However the rest $17 \%$ of them talk about hobbies/entertainment, and most of the gossips takes place in female analysis. The result for least percentage as shown above is Political/Current affairs. In conclusion, this shows that overall males are more likely to talk about office matters whereas females likes to gossip. However this is when Informal knowledge sharing takes place where people talk about their work, their lifestyle or just about anything in particular.

\subsubsection{How are lunch time conversations more beneficial than conversation with colleagues during office hours?}

Table 4.1.6 Lunch time conversation benefits compared to office hours

\begin{tabular}{|l|l|l|l|}
\hline \multicolumn{4}{|l|}{ Lunch time conversation benefits compared to office hours } \\
\hline Topic & Options & Frequency & Percentage \\
\hline $\begin{array}{l}\text { Lunch time } \\
\text { conversation } \\
\text { more } \\
\text { beneficial than } \\
\text { conversation } \\
\text { with office } \\
\text { colleagues }\end{array}$ & Free flow of information & 30 & $60 \%$ \\
\cline { 2 - 4 } & More insightful & 3 & $6 \%$ \\
\cline { 2 - 4 } & Freedom of thought & 17 & $34 \%$ \\
\hline
\end{tabular}

As illustrated in Table 4.1.6, the benefits reaped during lunch time conversation for Knowledge workers during lunch time are: $60 \%$ of them finds that having conversation outside office hours allow them to have more free flow of information. For example people feel free to express information's compared to office hours, however $34 \%$ of 
them feel it gives them freedom of thought to speak out more clearly and $6 \%$ of them feels it gives them more insightful and more understanding of what goes on inside the organization.

\subsubsection{Do you actively participate in conversation during lunch hour?}

Table 4.1.7 actively participate in conversation during lunch hour

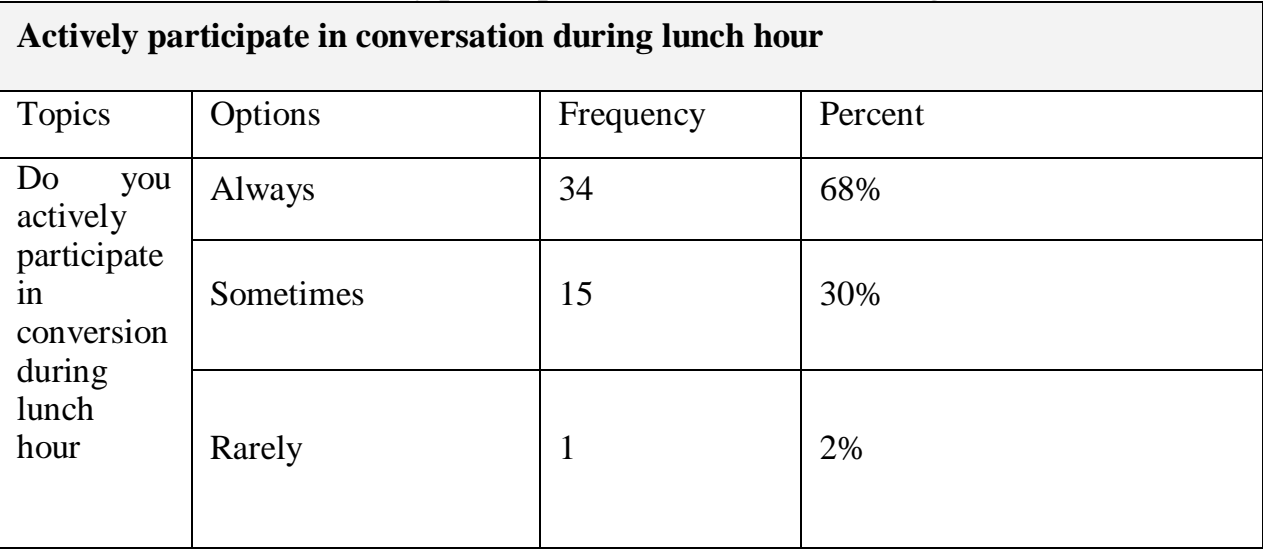

Based on the topic on actively participate in conversation during lunch hour, $68 \%$ of respondents mentioned that they always participate whenever they have lunch with their friends or office colleagues. However 30\% participates only times and $2 \%$ of them rarely participate. This shows that people do share their knowledge with their friends or office colleagues where they exchange ideas and thoughts with people whom they have lunch with always.

\subsubsection{How often do you gain useful information from conversations during lunch time?(female estimation)}

Table 4.1.8 Gain useful information from conversation during lunch hour (female estimation)

\begin{tabular}{|l|l|l|l|}
\hline $\begin{array}{l}\text { Gain useful information from conversation during lunch hour (Female } \\
\text { estimation) }\end{array}$ \\
\hline Topic & Options & Frequency & Percentage \\
\hline $\begin{array}{l}\text { How often do } \\
\text { you gain useful } \\
\text { information } \\
\text { from } \\
\begin{array}{l}\text { conversation } \\
\text { during lunch } \\
\text { time }\end{array}\end{array}$ & Always & 8 & $35 \%$ \\
\cline { 2 - 4 } & Sometimes & 14 & $61 \%$ \\
\hline
\end{tabular}

Based on Table 4.1.8 above, it can be illustrated that most respondents gain useful information sometimes which is $61 \%$ of them. However $35 \%$ of them always gain useful 
information when they interact with each other and only $4 \%$ shows that either rarely or never that they gain any information/knowledge.

\subsubsection{How often do you gain useful information from conversations during lunch time? (Male estimation)}

Table 4.1.9 Gain useful information from conversation during lunch hour (male's estimation)

\begin{tabular}{|l|l|l|l|}
\hline \multicolumn{4}{|l|}{ Gain useful information from conversation during lunch hour (male estimation) } \\
\hline Topic & Options & Frequency & Percentage \\
\hline $\begin{array}{l}\text { How often do } \\
\text { you gain useful } \\
\text { information } \\
\text { from } \\
\text { conversation } \\
\text { during lunch } \\
\text { time }\end{array}$ & Always & 17 & $63 \%$ \\
\cline { 2 - 4 } & Sometimes & 6 & $22 \%$ \\
\cline { 2 - 4 } & Rarely & 2 & $7 \%$ \\
\hline
\end{tabular}

Based on Table 4.1.9 above, it can be illustrated that most male respondents gain useful information always are $63 \%$ of them. However $22 \%$ of them always gain useful information when they interact with each other and only $7 \%$ shows that it's rarely that they don't gain any information/knowledge.

This can be concluded by saying compared to female's respondents; male respondents gain more useful information while having conversation with their friends or office colleagues. As it shows Males 63\% shares every time, while female are $61 \%$.

\subsubsection{Do you think having lunch conversation together strengthens relationships among colleagues in the company?(male analysis)}

Table 4.1.10 Strengthens relationship among colleagues during lunch conversation (male's analysis)

Strengthens relationship among colleagues during lunch conversation (males analysis)

\begin{tabular}{|l|l|l|l|}
\hline Topic & Option & Frequency & Percentage \\
\hline $\begin{array}{l}\text { Strengthens } \\
\text { relationship } \\
\text { with } \\
\text { colleagues }\end{array}$ & Always & 18 & $67 \%$ \\
\cline { 2 - 4 } & Sometimes & 6 & $22 \%$ \\
\cline { 2 - 4 } & Rarely & 2 & $7 \%$ \\
\hline
\end{tabular}

Table 4.1.10 above shows the views of people, about when having lunch conversation with office colleagues whether it strengthens relationships. The male results 
were comparatively different from females. It shows that $67 \%$ of the males said yes, that it always helps them to build their relationship when they share with office colleagues. Meanwhile 22\% says sometimes it helps them and 7\% of them says that its rarely that it doesn't help them to strengthen relationships.

4.1.11 Do you think having lunch conversation together strengthens relationships among colleagues in the company? (Female analysis)

Table 4.1.11 Strengthens relationship among colleagues during lunch conversation (female's analysis)

\begin{tabular}{|l|l|l|l|}
\hline $\begin{array}{l}\text { Strengthens relationship among colleagues during lunch conversation (female's } \\
\text { analysis) }\end{array}$ \\
\hline Topic & Option & Frequency & Percentage \\
\hline $\begin{array}{l}\text { Strengthens } \\
\text { relationship } \\
\text { with } \\
\text { colleagues }\end{array}$ & Always & 17 & $74 \%$ \\
\cline { 2 - 4 } & Sometimes & 6 & $26 \%$ \\
\cline { 2 - 4 } & Rarely & 0 & $0 \%$ \\
\hline
\end{tabular}

Female respondents had different views compared to males. However $74 \%$ of females thought that it always help them to strengthen relationship among colleagues during lunch conversation compared to males are $67 \%$ of them which is only almost half of that. Meanwhile, the rest $26 \%$ thinks sometimes it helps them and zero percent of them thinks it's rarely.

\subsubsection{Which of the following factors motivates you to have conversation during lunch hour? (Male analysis)}

Table 4.1.12 Factors motivates to have conversations during lunch hour (Male's analysis)

Factors motivates to have conversations during lunch hour (Male's analysis)

\begin{tabular}{|l|l|l|l|}
\hline Topic & Options & Frequency & Percentage \\
\hline $\begin{array}{l}\text { Factors } \\
\text { motivates to } \\
\text { have } \\
\begin{array}{l}\text { conversation } \\
\text { during lunch } \\
\text { hour }\end{array}\end{array}$ & The idea of receiving information & 5 & $19 \%$ \\
\cline { 2 - 4 } & The relationship with others & 21 & $78 \%$ \\
\cline { 2 - 4 } & Wanting to share information with others & 8 & $30 \%$ \\
\cline { 2 - 4 } & Development of new knowledge & 6 & $22 \%$ \\
\cline { 2 - 4 } & Increase Knowledge level & 4 & $15 \%$ \\
\hline
\end{tabular}

From the Table 4.1.12 above, it shows that most of the factors which motivate them to have conversation during lunch hour is: $78 \%$ thinks the relationship with others is important factor for them, however $30 \%$ of them wants to share information with others. Moreover $22 \%$ of males think it helps to develop new knowledge when sharing with others, $19 \%$ of them think the idea of receiving information when their friends or office colleagues talk about different topic as mentioned earlier about office matters, 
entertainment, politics and so on. While the least $15 \%$ of them thinks that having conversation increases their knowledge level.

\subsubsection{Which of the following factors motivates you to have conversation during lunch hour? (Female analysis)}

Table 4.1.13 Factors motivates to have conversations during lunch hour (Female's analysis)

\begin{tabular}{|l|l|l|l|}
\hline \multicolumn{3}{|l|}{ Factors motivates to have conversations during lunch hour (Female's analysis) } \\
\hline Topic & Options & Frequency & Percentage \\
\hline \multirow{2}{*}{$\begin{array}{l}\text { Factors } \\
\text { motivates to } \\
\text { have } \\
\text { conversation } \\
\text { during lunch } \\
\text { hour }\end{array}$} & The idea of receiving information & 8 & $35 \%$ \\
\cline { 2 - 4 } & The relationship with others & 14 & $61 \%$ \\
\cline { 2 - 4 } & Danting to share information with others & 12 & $52 \%$ \\
\cline { 2 - 4 } & Increase Knowledge level & 10 & $43 \%$ \\
\hline
\end{tabular}

From Table 4.1.13 above, it shows that most of the factors for female analysis which motivates them to have conversation during lunch hour is $61 \%$ who think that the relationship with others is important factor for them, however $52 \%$ of them want to share information with others. Moreover $43 \%$ of female think it helps to develop new knowledge when sharing with others, while $35 \%$ of them think the idea of receiving information when their friends or office colleagues talk about different topics as mentioned earlier about office matters, entertainment, politics and so on. The least $13 \%$ of them thinks that having conversation increases their knowledge level.

It can be concluded by saying that more males think that relationship is an important factor for them compared to female's percentage. While in females $52 \%$ of them think that sharing information with others is more important to them rather than considering the relationship factor.

\subsection{Summary of Data Analysis}

Respondents' view on the informal knowledge sharing during lunch hour inclined to the positive opinion. Overall $48 \%$ enjoyed having lunch with office colleagues and $44 \%$ of them enjoyed having lunch with their friends. The rest $6 \%$ enjoy having lunch with their family. Respondents who normally have lunch with the more than three people are about $40 \%$, however $30 \%$ have lunch with only three people and the rest of them, $20 \%$, have lunch with only one person. The least result shows that only $10 \%$ have it with one person.

The analysis on what knowledge workers mostly talk about during lunch hour showed that $52 \%$ of the males respondents mostly talked about their office matters as related to their companies project, development of the organizations, meetings and so on. Meanwhile $22 \%$ of them talk about hobbies/entertainment such as movies, fashions lifestyles etc. Furthermore $15 \%$ of them discuss about political/current affairs. Politics could be related to office politics or world politics. On the other hand, it shows that $4 \%$ of males gossips and last but not the least others are $7 \%$ which the respondent mentioned they talk about food, work or just about anything in general. The female analysis on what 
they talk about during lunch hour showed that $39 \%$ females talk about office matters compared to male's analysis, the rest $17 \%$ of them talk about hobbies/entertainment. Most of the gossips took place in female analysis. The result for least talked about as shown in the previous sections is political/current affairs. In conclusion of this shows that overall males are more likely to talk about office matter whereas females like to gossip.

The analysis on the benefits of the conversation with colleagues during lunch office hours has shown positive results. This analysis was related to the benefits people get when they share outside their workplace during lunch are: overall $60 \%$ of them find that having conversation outside office hours was where they have more free flow of information for example what people feel free to express information's compared to office hours, however $34 \%$ of them feel it gives them freedom of thought to speak out more clearly and 6\% of them feels its gives more insightful and more understanding of what goes on inside their organization.

Respondents view on active involvement in conversations during lunch hour showed that $68 \%$ of respondents said that they always participate whenever they have lunch with their friends or office colleagues. However $30 \%$ participates sometimes and the last result for this was that $2 \%$ of them rarely participate. This shows that people do share their knowledge with their friends or office colleagues they exchange ideas and their thoughts with the people whom they have lunch with always.

In finding out if knowledge workers do gain useful information while having conversation, female respondents gain useful information sometimes which are $61 \%$ of them. However $35 \%$ of them always gain useful information when they interact with each other and only 4\% shows that it's rarely that they don't gain any information/knowledge.

On the other hand, the male respondents for this analysis showed that $63 \%$ always gains useful information, $22 \%$ of them sometimes they gain useful information when they interact with each other and only 7\% shows that it's rarely that they don't gain any information/knowledge.

Meanwhile, the respondents' opinion about while having conversation together, does it strengthen relationships among colleagues in company showed that: Males $67 \%$ of them said yes, it always helps them to build their relationship when they share with office colleagues. Meanwhile 22\% says sometimes it helps them and $7 \%$ of them say that it is rarely that it doesn't help them to strengthen relationships.

As compared to male respondents, $74 \%$ of female respondents think it always help them to strengthen relationships among colleagues during lunch conversation compared to males which are $67 \%$ of them. The rest $26 \%$ thinks sometimes it helps them and zero percent of them thinks it's rarely.

The analysis on which factor motivates them to have conversation during lunch hours showed that $78 \%$ of the male respondents think that relationship with others is important factor for them, however $30 \%$ of them want to share information with others. Moreover $22 \%$ of males think it helps to develop new knowledge when sharing with others and $19 \%$ of them think that the idea of receiving information with their friends or office colleagues who talk about different topics as mentioned earlier about office matters, entertainment, political and so on. While the least $15 \%$ of them thinks that having conversation increases their knowledge level.

Furthermore, $61 \%$ of the female respondents think that relationship with others is important factor for them. However $52 \%$ of them want to share information with others. Moreover $43 \%$ of the females think it helps them to obtain new knowledge when sharing with others, while $35 \%$ of them think the idea of receiving information when their friends or office colleagues talks about different topics as mentioned earlier about office matters, entertainment, political and so on is beneficial. The least $13 \%$ of them thinks that having conversation increases their knowledge level. 
In conclusion of the data analysis, it proved that knowledge sharing do take places during lunch hour. Knowledge workers in the area of Cyberjaya converse about office matters, current affairs, sports, fashion, gossips and others during lunch time. Some of the respondents mentioned, "Yes sharing is important to get things right and also to get things straight."

\section{Conclusions and Recommendations}

Knowledge sharing through informal communication in Cyberjaya takes place during lunch hour compared to workplace. The MSC knowledge workers prefer sharing information outside the organization for various reasons. This process seems provide them more freedom to express information, thought, where people can discuss freely about anything. In addition, this research was started with an exploratory study during lunch hour in Cyberjaya which is is known for one of the world's first intelligent cities and the nerve centre of the MSC in Malaysia.

Knowledge sharing through informal communication among Malaysians is still new. It is part of our lives but most of the times it was not being discussed or realised. The culture itself does not emphasise more on it historically. People see knowledge sharing as a threat or burden, afraid of losing face, credibility, or, their position in organization. Worst, it is thought to be a formal discussion especially in organisations. The most important thing is actually to make knowledge sharing exciting for people, especially in knowledge management in organization. This is something crucial and truth for all society, including in Malaysia. The easiest way to start is to understand and accept the fact that it could happen through our daily information communication, through conversation specifically.

Informal communication like conversation during lunch hour builds trust and strengthens relationships between participants besides just a story telling session. It is a pre-requisite for effective knowledge sharing. Choosing and arranging the physical space of a conversation help to facilitate a certain type of conversation. For example, sitting in circles, blocking interruptions, holding meetings outside the organization, and, thinking outside the box. It also helps in improving the quality of conversations. The more you share the more knowledge you gain from others.

The two most important reasons why organisations should think about pursuing these informal mechanism is because it is remarkably effective, as up to $70 \%$ of workplace learning occurs in it. Therefore, informal knowledge is considered an important factor nowadays. It not only helps organizations in developing new knowledge, but also increases workers' knowledge level while maintaining their informal relationships with each other.

This study used primary data to investigate the knowledge sharing through informal communication during lunch hour in Cyberjaya; whether those MSC knowledge workers share knowledge or information, or not. Results had shown positively that knowledge sharing do takes place during lunch time, and it happened through informal communication. However, this research was restricted only to 50 people who are working in the MSC Cyberjaya area. This number can be increased for better results for future research. In order to attain more reliable findings for future improvements, other researchers may expand the scope to other parts of Malaysia, or to other countries to 
show whether any knowledge sharing takes place during lunch time, and more important, to see whether it happen through informal communication. One of the possible target could be any of the planned corridor in Malaysia such as Iskandar Malaysia in Johor.

\section{References}

1 Abdus S. C. (2005). Knowledge sharing practices in Asian institution a multi cultural perspective from Singapore. Retrieved June 1, 2008, from http://www.ifla.org/IV/ifla71/papers/066e-Chaudhry.pdf

2 Alavi, M., \& Leidner, D. E. (2001). Review: Knowledge management and knowledge management systems: Conceptual foundations and research issues. MIS Quarterly, 25(1), 107-136.

3 Berg, S.A., \& Chyung, S.Y. (2008) . Factors that influence informal learning in the workplace. Journal of Workplace Learning. 20(4), 229-244.

4 Choo, C.W., \& Bontis, N. (2002). Knowledge, intellectual capital, and strategy: Themes and tensions. In C.W. Choo, N. Bontis (Eds.). The Strategic Management of Intellectual Capital and Organizational Knowledge. NY: Oxford University Press.

5 Chowdhury, N. (2006). Building Knowledge Management in Malaysia. Inside Knowledge, 9(7). [online]: http://www.km4dev.org/index.php/articles/news/744

6 Chua, A. (2003). Knowledge Sharing: A Game People Play. Aslib proceedings : New information perspectives. 55(3), 117-129.

7 Computerliteracy.com. (2007). Microsoft Excel Version Release History. Computer Literacy [online]. Available:http://www.computerliteracy.co.uk/excel_versions.htm [2008 August 20]

8 Cook, S. D. N., \& Brown, J. S. (1999). Bridging epistemologies: The general dance between organizational knowledge and organizational knowing. Organization Science, 10(4), 381-400.

9 Cooper, R. D., \& Schindler, S. P. (2003). Business Research Methods. New Delhi: Tata McGraw-Hill Publishing Company Limited.

10 Davenport, T. H. \& Prusak, L. (1998). Working knowledge: How Organization manage what they know. Boston, Mass: Harvard Business School.

11 Digenti, D. (2000). Make space for informal learning. Available [Online] http://www.learningcircuits.org/2000/aug2000/digenti.html

12 Frankfort-Nachmias, C., \& Nachmias, D. (1996).Research Methods in the Social Sciences. $5^{\text {th }}$ edition. Great Britain's Martin's Press

13 Garrison, S. (2007). Getting Started with Excel. Study Finance [online]. Available: http://www.studyfinance.com/lessons/excel/index.mv [2008, August 15].

14 Gemmy, A. (1999). Tips for Collecting, Reviewing, and Analyzing Primary Data. Available

[online]: http://brent.tvu.ac.uk/dissguide/hm1u3/hm1u3text3.htm

15 Govendarajan, V., \& Lang, J.B. (2002). Southwest Airlines Corporation. Trustees of Dartmouth College [online].Available:http://mba.tuck.dartmouth.edu/pdf/2002-20012.pdf[2007,January 3]

16 Gurteen.com. (2009). Organizational Culture. [online]: http://www.gurteen.com/gurteen/gurteen.nsf/id/organizational-culture. 
17 Gurteen, D. (1999). Creating a Knowledge Sharing Culture. Provide sedge [online]

Available: http://www.providersedge.com/docs/km_articles/Creating_a_K-

Sharing_Culture_Gurteen.pdf [2008, August 19].

18 Mitchell, H. (2005). Knowledge Sharing the value of Storytelling. International Journal of Organizational Behaviour, 9(5), 632-641.

19 Holtshouse, D. (2006). The Future of the Future: The future workplace. Retrieved June 4, 2008, from http://www.kmworld.com/Articles/Column/Future-of-the-Future/The-future-of the-future --The -future- workplace- 15811.aspx

20 Jewels,T., Underwood, A. \& de Pablos, C.(2003). The Role of Informal Networks and Knowledge sharing. Proceedings of the 11th European Conference on Information Systems, Naples, Italy.

21 Lawson, S. (2003). Examining the relationship between Organizational Culture and Knowledge Management. Doctoral dissertation, Nova South-eastern University,.Dissertations Abstract International, 64/08, 2975.

22 Marouf, L.N. (2007). Social networks and knowledge sharing in organizations. Journal of Knowledge Management, 11(6), 110-125.

23 Mengis, J. \& Eppler, M.J. (2005). Understanding and Enabling Knowledge Sharing in Conversations: A literature Review and Management Framework . University of lugano, Switzerland.

24 MSC Malaysia (2008). History about MDEC. Available [online] http://www.mscmalaysia.my/topic/About+MDeC

25 Naaranoja. M. \& Sandhu, M. (2007). Challenges in Knowledge Management Sharing in Project Business. Proceeding at the $2^{\text {nd }}$ International Conference on Knowledge Management in Organization (KMO2007). University of Salento, Italy.

26 Neocyber (2009). About Cyberjaya. http://www.neocyber.com.my/(S(jlrjgev5qmhg51aeoaahjd25))/about_cyberjaya/ default.aspx

27 Nonaka, I., \& Takeuchi, H. (1995). The knowledge-creating company. How Japanese companies create the dynamics of innovation. New York: Oxford University Press.

28 No Doubt Research (2001), "The 'water cooler' as a metaphor: getting tacit knowledge flowing", paper presented at IIR's 3rd Annual Knowledge Management Conference, The Heritage Hotel, Auckland.

29 O'Dell, C.S. \& Grayson, C.F. (1998). If only we knew what we know: The transfer of internal knowledge and best practices. New York: Free Press.

30 Sauve,,E. (2007). Informal Knowledge Transfer. $T+D$, 3, 22-24.

31 Sharratt,M., \& Usoro, A. (2003). Understanding Knowledge-Sharing in Online Communities of Practice. Electronic Journal on Knowledge Management , 1(2), 187-196.

32 Stanley. R. (2005). How to Research $-A$ Guide for Undergraduate and Graduate Students. Thomas Learning.

33 Steinlin, M. (2005). Knowledge management Feng Shui: designing knowledge sharing-friendly office space. KM4D Journal, 1(2), 108-112.

34 Walsh, J. P., \& Ungson, G. R. (1991). Organizational Memory. Academy of management review, 16(1), 57-91.

35 Weick, K. E. (1979). The social psychology of organizing (2nd ed.). Reading, MA: McGraw Hill. 
36 Woods, P. (2008) Leverage on Diversity: Lessons Learnt in Malaysia's Multimedia Super corridor. The 4th International Research Conference on Asian Business, Singapore.

37 Yang, J.T. (2004). Job-related Knowledge Sharing: comparative case studie., Journal of Knowledge Management, 8(3), 118-126.

38 Zainnudin, M. (1997). Place in Urban Development and Regeneration Multimedia Super Corridor Vision. Paper presented at the INTA 21 Annual Conference Lisbon Portugal, 21-25. 